\title{
Expression of the costimulatory molecule B7-H3 is associated with prolonged survival in human pancreatic cancer Martin Loos ${ }^{\dagger 1}$, Dennis M Hedderich ${ }^{\dagger 1}$, Malte Ottenhausen ${ }^{1}$, Nathalia A Giese ${ }^{3}$, Melanie Laschinger ${ }^{1}$, Irene Esposito ${ }^{2}$, Jörg Kleeff ${ }^{1}$ and Helmut Friess*1
}

Address: ${ }^{1}$ Department of Surgery, Klinikum rechts der Isar, Technische Universität München, Ismaninger Str 22, 81675 Munich, Germany, ${ }^{2}$ Department of Pathology, Klinikum rechts der Isar, Technische Universität München, Ismaninger Str 22, 81675 Munich, Germany and ${ }^{3}$ Department of General Surgery, University of Heidelberg, Im Neuenheimer Feld 110, 69120, Heidelberg, Germany

Email: Martin Loos - loos@chir.med.tu-muenchen.de; Dennis M Hedderich - dennis.hedderich@gmx.de; Malte Ottenhausen - MalteOttenhausen@web.de; Nathalia A Giese - Nathalia.Giese@chirurgie.med.uni-heidelberg.de; Melanie Laschinger - Laschinger@chir.med.tu-muenchen.de; Irene Esposito - Irene.Esposito@helmholtz.de; Jörg Kleeff - kleeff@chir.med.tumuenchen.de; Helmut Friess* - Helmut.Friess@chir.med.tu-muenchen.de

* Corresponding author †Equal contributors

Published: 26 December 2009

BMC Cancer 2009, 9:463 doi:10.1 186/147|-2407-9-463
Received: 26 July 2009

Accepted: 26 December 2009

This article is available from: http://www.biomedcentral.com/147I-2407/9/463

(c) 2009 Loos et al; licensee BioMed Central Ltd.

This is an Open Access article distributed under the terms of the Creative Commons Attribution License (http://creativecommons.org/licenses/by/2.0), which permits unrestricted use, distribution, and reproduction in any medium, provided the original work is properly cited.

\begin{abstract}
Background: Costimulatory signaling has been implicated as a potential regulator of antitumor immunity in various human cancers. In contrast to the negative prognostic value of aberrant B7-HI expression by pancreatic cancer cells, the role of $\mathrm{B} 7-\mathrm{H} 3$ is still unknown. Therefore, we investigated the expression pattern and clinical significance of $\mathrm{B} 7-\mathrm{H} 3$ expression in human pancreatic cancer.

Methods: $\mathrm{B} 7-\mathrm{H} 3$ expression was evaluated by immunohistochemistry in 68 patients with pancreatic cancer who underwent surgical tumor resection. Expression data was correlated with clinicopathologic features and with the number of tumor-infiltrating $T$ cells.

Results: $\mathrm{B} 7-\mathrm{H} 3$ expression was significantly upregulated in pancreatic cancer compared to normal pancreas $(p<0.05)$. In 60 of 68 examined tumors B7-H3 protein was detectable in pancreatic cancer cells. Patients with high tumor B7-H3 levels had a significantly better postoperative prognosis than patients with low tumor B7-H3 levels $(p=0.0067)$. Furthermore, tumor B7-H3 expression significantly correlated with the number of tumor-infiltrating $C D 8+T$ cells $(P=0.018)$.

Conclusion: We demonstrate for the first time that $\mathrm{B} 7-\mathrm{H} 3$ is abundantly expressed in pancreatic cancer and that tumor-associated $\mathrm{B} 7-\mathrm{H} 3$ expression significantly correlates with prolonged postoperative survival. Our findings suggest that $\mathrm{B} 7-\mathrm{H} 3$ might play an important role as a potential stimulator of antitumor immune response in pancreatic cancer.
\end{abstract}

\section{Background}

Pancreatic cancer is one of the most devastating human malignancies. At present, pancreatic cancer is the fourth leading cause of cancer-related deaths in the U.S. [1]. Despite great efforts on clinical and molecular pancreatic cancer research, the prognosis remains poor with an over- 
all 5-year-survival of less than 5\% [2]. Complete surgical resection still represents the only potentially curative treatment [3]. By the time of diagnosis, however, only few patients are candidates for surgery.

The capability to modulate or even suppress antitumor immune responses is a characteristic feature enabling malignant tumors to evade immune surveillance and subsequent destruction [4-6]. Costimulatory signaling plays a key role in the initiation and termination of immune responses by regulation of $\mathrm{T}$ cell priming, growth, maturation, and tolerance [7]. One of the best characterized costimulatory pathways includes B7-1/B7-2:CD28 signaling [7]. Engagement of B7-1 on antigen-presenting cells with CD28 on T cells enhances T cell proliferation and IL-2 production. In the absence of this simultaneous costimulatory signal, ligation of the $T$ cell receptor by an antigenic peptide results in T cell dysfunction, intolerance or anergy [7]. Beside positive costimulatory signals that augment and sustain $\mathrm{T}$ cell response, costimulatory pathways also deliver inhibitory signals which downregulate $\mathrm{T}$ cell response. Binding of CTLA- 4 to B7-1 and/or B7-2 has been shown to inhibit IL-2 synthesis and progression through the cell cycle leading to the termination of $\mathrm{T}$ cell response $[7,8]$.

Within the past decade, new costimulatory ligands and receptors have been identified including B7-H1 (programmed death-1 ligand-1), B7-DC (programmed death1 ligand-2), PD-1 (programmed death-1), B7-H3, and B7$\mathrm{H} 4[9,10]$. In contrast to the well-defined roles of B7-1 and B7-2 as essential costimulators involved in T cell activation, the function of B7-H1, B7-DC, B7-H3, and B7-H4 is less clear. Recently, B7 homologues have been implicated as potential regulators of antitumor immunity [4]. Numerous human cancers have been reported to aberrantly express B7-H1 [11-14]. Aberrant B7-H1 expression by tumor cells has been associated with adverse pathologic features and poor outcome $[15,16]$. We and others have previously shown that pancreatic cancer patients with cancer-cell associated B7-H1 expression had a significantly poorer prognosis than patients with $\mathrm{B} 7-\mathrm{H} 1$ negative tumors $[12,13]$. Thus, aberrant expression of $\mathrm{B} 7-\mathrm{H} 1$ has been postulated as a potential mechanism by which malignant tumors may evade the host immune response. A possible explanation for the tumor-associated immune suppression is that aberrant expression of B7-H1 might downregulate tumor-specific T cell response by inducing $\mathrm{T}$ cell anergy or apoptosis.

In contrast to the negative prognostic value of aberrant B7-H1 expression by tumor cells, the role of $\mathrm{B} 7-\mathrm{H} 3$ in human cancers is controversial. B7-H3 is a B7 homologue that shares approximately $25 \%$ sequence homology with B7-H1. In contrast to B7-H3 mRNA, which is broadly expressed in lymphoid and non-lymphoid organs, B7-H3 protein expression seems to be limited. Functionally, B7$\mathrm{H} 3$ is thought to serve as an accessory costimulatory regulator of $\mathrm{T}$ cell responses following initial $\mathrm{T}$ cell priming. However, its exact physiologic role is still unclear, because both stimulatory and inhibitory properties have been described. Initially, it has been reported that human B7$\mathrm{H} 3$ costimulates proliferation of both $\mathrm{CD} 4+$ and CD8+ T cells, enhances the induction of cytotoxic $\mathrm{T}$ cells, and selectively stimulates IFN- $\gamma$ production in the presence of $\mathrm{T}$ cell receptor signaling [17]. In mice, however, B7-H3 inhibits proliferation of both CD4+ and CD8+ T cells and IFN- $\gamma$ production [18]. In accordance to its inconsistent immunologic function, the role of $\mathrm{B} 7-\mathrm{H} 3$ in cancer remains far from clear. For example, transfection of B7-H3 into P815 tumor cells led to the regression of tumors and amplification of a tumor-specific CD8+ cytotoxic lymphocyte response in syngeneic mice [19]. In another experimental study, adenoviral B7-H3 treatment resulted in a reduction of tumor size and a significant reduction of secondary metastases in an orthotopic murine colon cancer model [20]. In a model of EL-4 lymphoma, injection of a B7-H3 expression plasmid into the tumor resulted in complete regression of $50 \%$ of tumors [21]. The response depended upon CD8+ T cells and NK cells [21]. In contrast to these tumor-protective effects of B7-H3, tumor B7H3 expression in human non-small-cell lung cancer inversely correlated with the number of tumor-infiltrating lymphocytes and significantly correlated with lymph node metastases [22]. In prostate cancer, two studies analyzing B7-H3 expression in a considerable number of patients revealed that almost all examined tumors expressed B7-H3 protein. Both studies showed a significant correlation between high B7-H3 expression by tumor cells and disease spread and poor outcome $[23,24]$.

Here, we show for the first time that $\mathrm{B} 7-\mathrm{H} 3$ is abundantly expressed in pancreatic cancer and that B7-H3 expression by pancreatic cancer cells correlates with increased patient survival as well as with the number of tumor-infiltrating CD8+ T cells.

\section{Methods \\ Patients}

All tissue specimens analyzed in this study were obtained according to institutional review board-approved procedures for consent. Human pancreatic cancer tissue samples were obtained from 96 patients ( 39 female and 57 male patients with a median age of 63 years; age range, 3883 years), who underwent resection for pancreatic cancer at the University Hospital of Heidelberg (Heidelberg, Germany) between 2001 and 2006. Two patients presented with stage IB, 11 patients presented with stage IIA disease, 70 patients presented with stage IIB disease, two patients presented with stage III disease, and 11 patients presented 
with stage IV disease according to the UICC classification (6th edition, 2002). The median follow-up was 23 months, with a range from 2 to 44 months. Normal human pancreatic tissue samples were obtained through an organ donor program from 10 previously healthy individuals (four female, six male; median age of 43 years, with a range of 17-62 years) when there was no suitable recipient.

\section{Tissue Sampling}

Immediately after surgical removal, tissue samples were either snap-frozen in liquid nitrogen (for RNA and protein extraction) or fixed in $10 \%$ buffered formalin solution and embedded in paraffin for histological analysis. A serial section of each specimen was stained with H\&E for histological evaluation. In addition, a portion of the tissue specimen was preserved in RNAlater (Ambion Europe Ltd., Huntington, Ambridgeshire, UK).

\section{Cell culture}

Panc-1, MiaPaCa-2 and SU86.86 pancreatic cancer cells were grown routinely in RPMI 1640 with L-glutamine and 25 mM HEPES (Gibco, Karlsruhe, Germany) supplemented with 10\% fetal bovine serum (FBS), $100 \mathrm{U} / \mathrm{ml}$ penicillin, and $100 \mu \mathrm{g} / \mathrm{ml}$ streptomycin (Invitrogen, Karlsruhe, Germany) and incubated in a $5 \% \mathrm{CO}_{2}$ humidified atmosphere.

\section{Quantitative RT-PCR}

All reagents and equipment for mRNA/cDNA preparation were purchased from Roche Applied Science (Mannheim, Germany). Messenger-RNA was prepared by automated isolation using MagNA Pure LC instrument and isolation kits I (for cells) and II (for tissues). Complementary-DNA was prepared using the First Strand cDNA Synthesis Kit for reverse transcription-PCR according to the manufacturer's instructions. Real-time PCR was performed with the LightCyclerFastStart DNA SYBR Green kit as described previously [25]. B7-H3, CD4, CD8, and IFN- $\gamma$ primers were obtained from Search-LC (Heidelberg, Germany). The number of specific transcripts was normalized to the average expression of two housekeeping genes (cyclophillin B and hypoxanthine-guanine phosphoribosyltransferase) [25]. The data of two independent analyses for each sample and parameter were averaged and presented as adjusted transcripts/ $\mu \mathrm{l}$ cDNA.

\section{Antibodies/Immunohistochemistry}

Immunohistochemical analyses were carried out with mouse anti-human B7-H3 antibody (MAB 1027, R\&D Systems, Minneapolis, MN), mouse anti-human CD4 antibody (1F6, Monosan, Uden, Netherlands), and mouse anti-human CD8 antibody (DAKO Diagnostics AG, Zürich, Switzerland). Antigen retrieval was achieved by microwave pre-treatment in citrate buffer. Paraffin- embedded pancreatic tissue sections (3- $\mu$ m thick) were deparaffinized with xylene and rehydrated through graded alcohol into distilled water. After washing in Trisbuffered saline, endogenous peroxidase activity was quenched by incubating the slides in 3\% hydrogen peroxide in methanol. To block unspecific activity of secondary antibodies, slides were treated with TBS/3\%BSA. After overnight incubation at $4{ }^{\circ} \mathrm{C}$ with the primary antibody, slides were washed with Tris-buffered saline and $0.05 \%$ Tween 20, treated with anti-mouse (DAKO) horseradish peroxidase-labeled secondary antibody for 1 hour, developed using Dako Envision System (DAKO), and counterstained with Mayer's hematoxylin. To ensure antibody specificity, negative control slides were incubated with normal mouse IgG. Immunohistochemistry results were evaluated by scanning each slide under low power magnification $(\times 10)$ to identify regions containing positive immunoreactivity. Immunostaining was further evaluated at high power magnification $(\times 200)$. Tumor samples were examined by two observers in a blind manner.

\section{Semi-quantitative analysis of B7-H3 expression in tissues and its correlation with patient survival}

To assess the impact of $\mathrm{B} 7-\mathrm{H} 3$ protein expression by cancer cells on patient survival, tissue blocks of 68 histologically confirmed pancreatic cancer patients were analyzed by immunohistochemistry. Evaluation of B7-H3 staining in cancer cells was made semi-quantitatively as published by Erkan M and co-workers [25]. Scores were given separately for the stained area and for the intensity of staining. Quantification was made as follows; $\leq 33 \%$ of the cancer cells: $1,>33$ to $\leq 66 \%$ of the cancer cells: $2,>66 \%$ of the cancer cells: 3 ; intensity of staining: absent/weak: 1 , moderate: 2, strong: 3. Each section had a final grade that derived from the multiplication of the area and intensity scores. Sections with a final score of $\leq 3$ were classified as tumors with low B7-H3 expression, whereas sections with a final score of $>3$ were classified as tumors with high B7H3 expression.

Semi-quantitative evaluation of the prevalence of tumorinfiltrating CD4+ and CD8+ $T$ cells in pancreatic cancer tissues and correlation with B7-H3 expression

To examine whether tumor B7-H3 expression is associated with the infiltration of $\mathrm{CD} 4+$ or $\mathrm{CD} 8+\mathrm{T}$ cells, we semi-quantitatively evaluated the prevalence of CD4+ and CD8+ cells in pancreatic cancer specimens. Consecutive slides from the same tumor were stained for CD4, CD8, and B7-H3. Using histological landmarks, corresponding areas with tumor B7-H3 and without tumor B7-H3 expression were identified under low power magnification $(\times 10)$. The prevalence of CD4+ or CD8 $+\mathrm{T}$ cells was semi-quantitatively evaluated at high power magnification $(\times 400)$ according to the number of CD4 positive or CD8 positive cells per areas: Areas with 0-5 CD4 positive 
or CD8 positive cells were recorded as (0), areas with 6-15 CD4 positive or CD8 positive cells were recorded as (1), and areas with $>15$ CD4 positive or CD8 positive cells were recorded as (2). Tumor samples were examined by two observers in a blind manner.

\section{Induction of B7-H3 in cultured pancreatic cancer cell lines and FACS analysis}

To determine the effect of IFN- $\gamma$ (R\&D Systems) or IL-4 (R\&D Systems) on the expression of B7-H3 in cultured pancreatic cancer cells, Panc-1, MiaPaCa-2, and SU86.86 cells were seeded in 6 -well plates (100,000 cells per well), and incubated with $2000 \mathrm{IU} / \mathrm{ml}$ of recombinant IFN- $\gamma$ or $40 \mathrm{ng} / \mathrm{ml}$ of recombinant IL- 4 for 24 or 48 hours. Cells were harvested and stained with anti-human B7-H3-FITC mAb (R\&D Systems) or control anti-human IgG-FITC (BD Pharmingen, Heidelberg, Germany). Single-color flow cytometry was performed by using a FACSCalibur (Becton-Dickinson, BD) and analyzed with FlowJo Software (Tree Star).

\section{Statistical Analysis}

Results are expressed as mean \pm SD (mRNA expression). For statistical analysis, GraphPad Prism software (GraphPad Software, San Diego, CA) was used. The Mann-Whitney U test, $\chi^{2}$ test or Spearman rho test were performed for comparative statistical evaluations among groups and for correlation analysis with histological and clinical parameters (age, gender, tumor stage, tumor grade, and postoperative survival). Significance was defined as $\mathrm{p}<0.05$. The Kaplan-Meier method was used to estimate the probability of survival, and significance was assessed by the logrank test.

\section{Results \\ Expression of the costimulatory molecule B7-H3 in human pancreatic cancer}

Quantitative RT-PCR was performed to assess mRNA expression of the costimulatory molecule B7-H3 in 28 surgically resected human pancreatic cancer tissue specimens and 10 normal human pancreatic tissue specimens. B7-H3 mRNA was significantly upregulated in pancreatic cancer tissues (275.5 transcripts \pm 44.4 ) compared to normal pancreatic tissue samples $(86.5 \pm 22.2 ; \mathrm{p}<0.05)$. To confirm the qRT-PCR data and to assess the location of B7-H3 protein, we performed immunostainings of 68 pancreatic cancer tissue samples. In pancreatic cancer tissues, abundant positive B7-H3 immunoreactivity could be detected in pancreatic cancer cells (Fig. 1), pancreatic islet cells, tumor-infiltrating immune cells, and sporadical weak immunoreactivity in tumor-surrounding tubular complexes and endothelial cells. Among the examined 68 pancreatic cancer tissues, 60 showed positive B7-H3 protein expression in pancreatic cancer cells. According to the
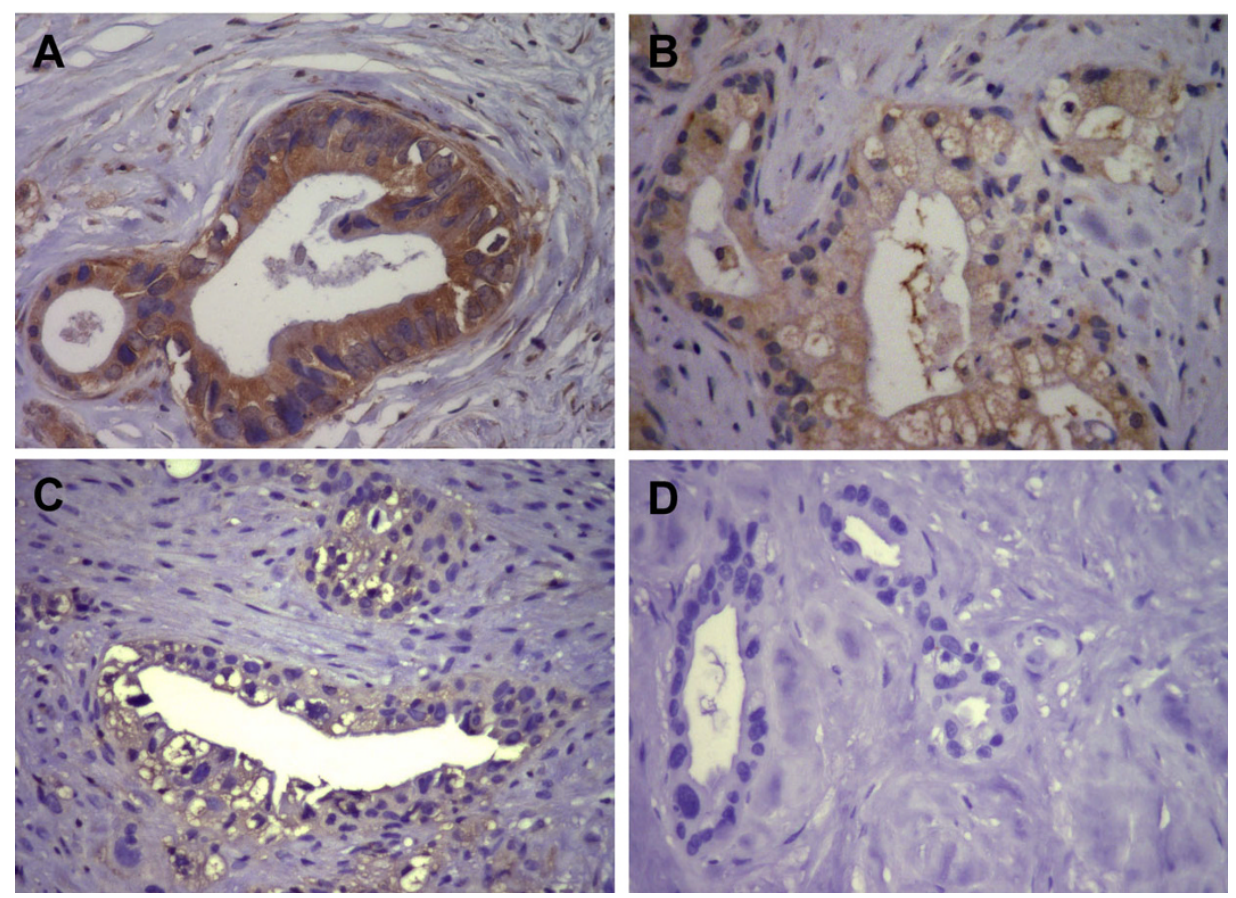

Figure I

Immunohistochemical characterization of B7-H3 expression in 4 representative human pancreatic cancer tissue sections. Positive B7-H3 immunoreactivity was detectable in pancreatic cancer cells (brown staining). Representative tissue sections of strong intensity (A), moderate intensity (B), and weak intensity (C). (D) Negative control. 
staining intensity, all specimens were classified into three groups with either no or weak, moderate or strong immunoreactivity (Fig. 1). Depending on the area of positive immunoreactivity, a final overall score (high tumor B7H3 or low tumor B7-H3 expression) was established as described in the methods section. In normal pancreatic tissues, weak B7-H3 protein expression could be sporadically detected in normal pancreatic acinar and ductal cells.

\section{B7-H3 expression correlates with better postoperative} survival in pancreatic cancer patients

Costimulatory signaling has been implicated as a possible regulator of antitumor immunity in several human malignancies. We investigated the relationship between tumorassociated B7-H3 protein expression and various clinicopathological features in pancreatic cancer (Table 1). No correlation could be observed between tumor B7-H3 expression and age, gender, tumor stage, and tumor grade. In contrast, high tumor B7-H3 expression was associated with significantly prolonged postoperative survival in pancreatic cancer patients $(\mathrm{p}=0.0067$; Fig. 2$)$. Among the examined 68 pancreatic cancer tissues, 40 showed low tumor B7-H3 expression, whereas 28 showed high tumor B7-H3 expression. The median survival in patients with high tumor B7-H3 expression was 17.8 months and 11.0 months in patients with low B7-H3 expression (Fig. 2).

IFN- $\gamma$ is upregulated in human pancreatic cancer in vivo and significantly correlates with tumor B7-H3 expression In vitro, B7-H3 has been shown to selectively stimulate IFN- $\gamma$ production by purified human T lymphocytes [17].

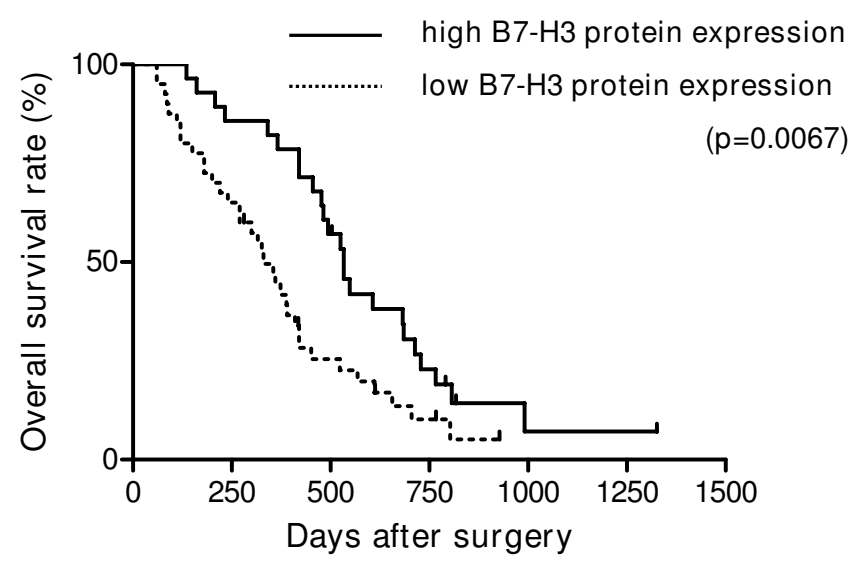

Figure 2

Overall survival of 68 pancreatic cancer patients in relation with $\mathrm{B} 7-\mathrm{H} 3$ protein expression. Patients with high tumor B7-H3 protein expression had a significantly better prognosis than patients without or with low tumor B7$\mathrm{H} 3$ protein expression $(\mathrm{p}=0.0067)$. The median survival of patients with high tumor $\mathrm{B} 7-\mathrm{H} 3$ protein expression was $\mathbf{I 7 . 8}$ months in contrast to 11.0 months in patients without or with low tumor B7-H3 protein expression.
Table I: Clinicopathological characteristics according to tumor B7-H3 expression.

\begin{tabular}{|c|c|c|c|c|}
\hline \multirow[b]{2}{*}{ Variable } & \multicolumn{3}{|c|}{ B7-H3 expression } & \multirow[b]{2}{*}{ p-value } \\
\hline & $\mathbf{n}$ & low & high & \\
\hline Gender & & & & n.s. \\
\hline Female & 24 & 16 & 8 & \\
\hline Male & 44 & 25 & 19 & \\
\hline Tumor status & & & & n.s. \\
\hline $\mathrm{TI}$ & 0 & 0 & 0 & \\
\hline T2 & 4 & 3 & 1 & \\
\hline T3 & 62 & 36 & 26 & \\
\hline $\mathrm{T} 4$ & 2 & I & I & \\
\hline Nodal status & & & & n.s. \\
\hline No & 10 & 5 & 5 & \\
\hline $\mathrm{NI}$ & 58 & 35 & 23 & \\
\hline Metastatic status & & & & n.s. \\
\hline MO & 58 & 35 & 23 & \\
\hline MI & 10 & 4 & 6 & \\
\hline Tumor grade & & & & n.s. \\
\hline GI & 2 & I & 1 & \\
\hline G2 & 44 & 27 & 17 & \\
\hline G3 & 22 & 12 & 10 & \\
\hline G4 & 0 & 0 & 0 & \\
\hline Survival (in months) & & 11 & 17,8 & $P=0.0067$ \\
\hline
\end{tabular}

To examine whether B7-H3 expression is associated with IFN- $\gamma$ levels in vivo, we analyzed cytokine gene expression of B7-H3 and IFN- $\gamma$ by qRT-PCR in 28 pancreatic cancer tissue samples and 10 normal pancreatic tissue samples. Gene expression of IFN- $\gamma$ was significantly upregulated in pancreatic cancer tissues in comparison to normal pancreatic tissues ( $\mathrm{p}<0.05$; Fig. 3A). Correlation analysis revealed a statistically significant correlation between $B 7$ $\mathrm{H} 3$ and IFN- $\gamma$ expression $(\mathrm{p}=0.0225$; Spearman rho 0.4297; Fig. 3B).

Cultured pancreatic cancer cell lines Panc-I, MiaPaCa-2, and SU86.86 constitutively express B7-H3

To test whether pancreatic cancer cells express the costimulatory molecule B7-H3 in vitro, we performed qRT-PCR. All tested cultured pancreatic cancer cell lines constitutively expressed B7-H3 mRNA under normal conditions (Panc-1 541 transcripts \pm 36.6, MiaPaCa-2 358 transcripts \pm 17.5 , SU86.86 743 transcripts \pm 725 ).

\section{Treatment of cultured SU86.86 pancreatic cancer cells with IFN- $\gamma$ or IL-4 markedly increases their B7-H3 expression}

To assess the effect of the Th 1 and Th 2 cytokines IFN- $\gamma$ and IL-4 on B7-H3 expression by cultured pancreatic cancer cells, cells (representative pancreatic cancer cell lines Panc-1 and SU86.86) were incubated with recombinant 


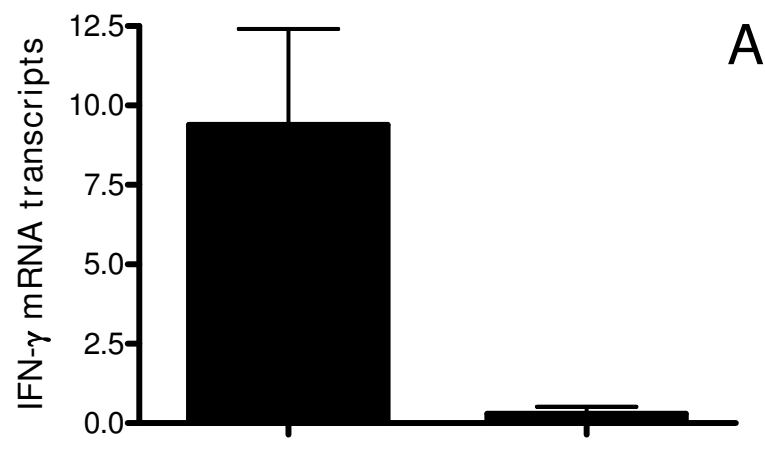

Pancreatic cancer $(n=28) \quad$ Normal pancreas $(n=10)$

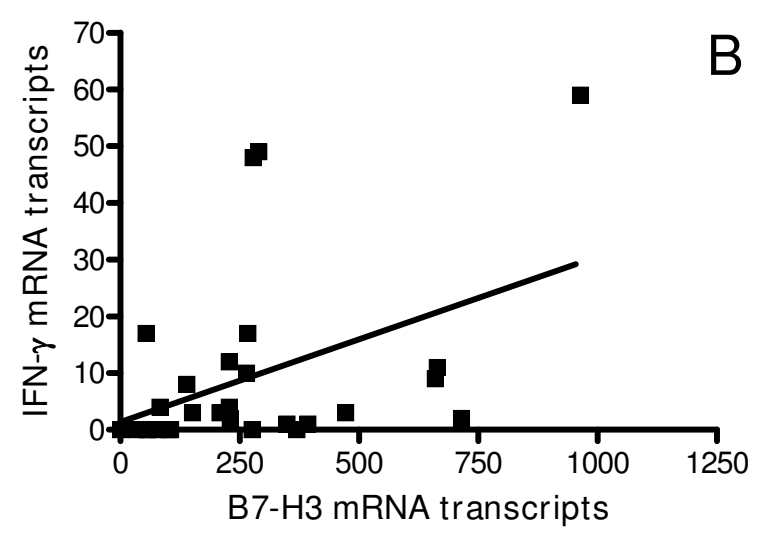

Figure 3

IFN- $\gamma$ mRNA expression in 28 pancreatic cancer tissues and 10 normal pancreatic tissues. (A) IFN- $\gamma$ mRNA expression was significantly upregulated in pancreatic cancer tissues compared to normal pancreas $(p<0.05)$. (B) Correlation analysis of B7-H3 mRNA and IFN- $\gamma$ mRNA expression in pancreatic cancer $(n=28)$ revealed a positive correlation between B7-H3 and IFN- $\gamma$ mRNA expression ( $P$ $=0.0225$; Spearman rho 0.4297).

IFN- $\gamma$ and IL- 4 for 24 and 48 hours. Treatment of Panc- 1 cells with IFN- $\gamma$ slightly decreased the expression of B7-H3 after 24 hours. The effect nearly disappeared after 48 hours (Fig. 4A). In SU86.86 cells IFN- $\gamma$ treatment resulted in a marked increase of B7-H3 expression after 24 hours which slightly decreased after 48 hours (Fig. 4B). IL-4 treatment similarly led to a slight decrease of $\mathrm{B} 7-\mathrm{H} 3$ expression in Panc- 1 cells after 24 hours which was more pronounced after 48 hours (Fig. 4C) in contrast to SU86.86 cells in which IL-4 exposure resulted in a marked increase after 24 hours with an amplification of B7-H3 expression after 48 hours (Fig. 4D). Thus, in contrast to Panc- 1 cells, treatment with IFN- $\gamma$ and more pronounced treatment with IL-4 increased expression of B7-H3 on the surface of SU86.86 cells.

\section{B7-H3 protein expression correlates with the number of} CD8+ $T$ cells in human pancreatic cancer tissues

To determine the potential relevance of $\mathrm{B} 7-\mathrm{H} 3$ expression on the distribution of CD4+ or CD8+ T cells in pancreatic cancer, we first examined mRNA levels of CD4 and CD8 in 28 pancreatic cancer tissue specimens and 10 normal pancreatic tissue specimens. Gene expressions were markedly increased in pancreatic cancer tissues compared to normal pancreatic tissues (CD4: 150 transcripts \pm 28.1 in pancreatic cancer vs. 52 transcripts \pm 12.4 in normal pancreas; CD8: 171 transcripts \pm 30.2 in pancreatic cancer vs. 39 transcripts \pm 6.4 in normal pancreas). B7-H3 mRNA expression significantly correlated with CD4 ( $\mathrm{p}<0.0001$, Spearman rho 0.76) and CD8 mRNA levels ( $\mathrm{p}<0.0097$, Spearman rho 0.48). To determine whether the expression of B7-H3 by pancreatic cancer cells influences the distribution of tumor-infiltrating CD4+ or CD8+ T cells, we performed immunohistochemical stainings for B7-H3, CD4, and CD8 of 20 randomly chosen pancreatic cancer tissue sections. Immunohistochemistry analysis revealed a significant correlation between the level of tumor B7-H3 expression and the number of tumor-infiltrating CD8+ T cells ( $p=0.018$; Fig. 5 and 6 ). No correlation could be observed between the level of tumor B7-H3 expression and the number of tumor-infiltrating CD4+ T cells.

\section{Discussion}

Pancreatic cancer is one of the most aggressive human malignancies and still represents a major therapeutic challenge. Despite the infiltration of large numbers of immune cells into pancreatic cancer, the immune system fails to prevent disease development and progression. Recently, dysregulation of immune responses by aberrant expression of negative costimulatory molecules by tumor cells has been suggested to play a potential role in the evasion of tumors from the immune system $[4,5]$. For example, tumor B7-H1 expression has been shown to significantly correlate with negative outcome in several human malignancies, including pancreatic cancer $[11,13$ 16]. B7-H3 is another member of the B7 family of costimulatory molecules which serves as an accessory costimulatory regulator of $\mathrm{T}$ cell responses following initial $\mathrm{T}$ cell priming. The exact physiological function of B7-H3 and especially its role in the development and progression of human cancers are still elusive.

In this study, we demonstrated that the cultured pancreatic cancer cell lines Panc-1, MiaPaCa-2, and SU86.86 constitutively express B7-H3. Moreover, we demonstrated that B7-H3 gene expression is upregulated in pancreatic cancer tissues in comparison to normal pancreatic tissues. Immunohistochemical analysis revealed B7-H3 protein expression by pancreatic cancer cells. Tumor cell-associated B7-H3 expression significantly correlated with better postoperative survival. Moreover, we showed that B7-H3 
Panc-1
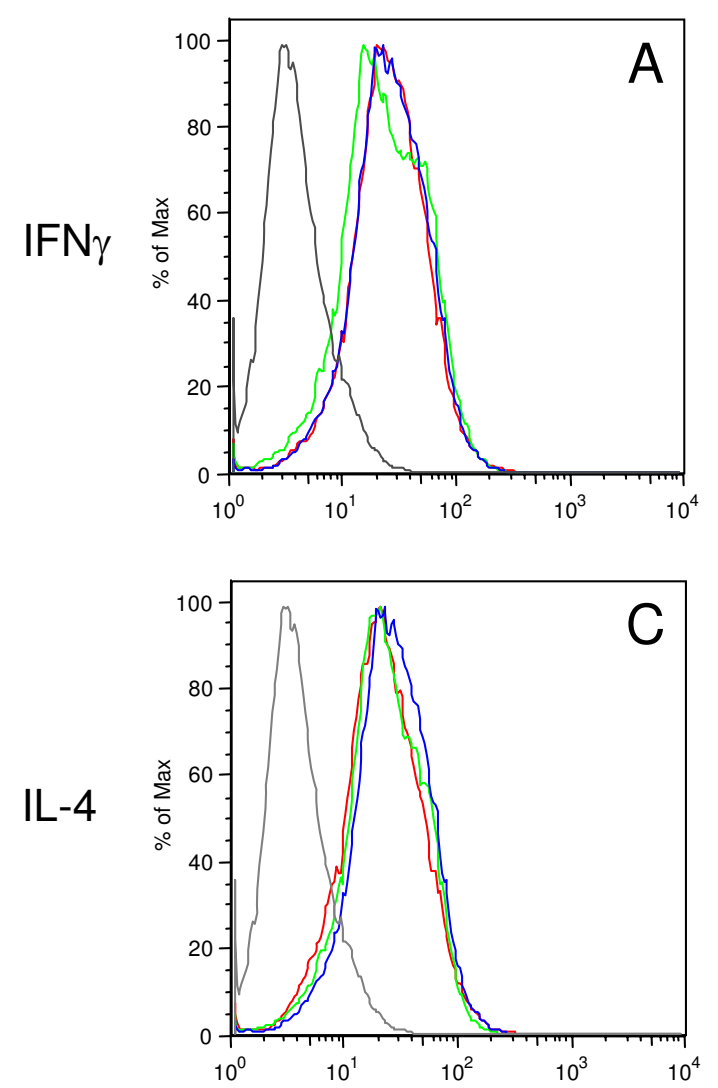
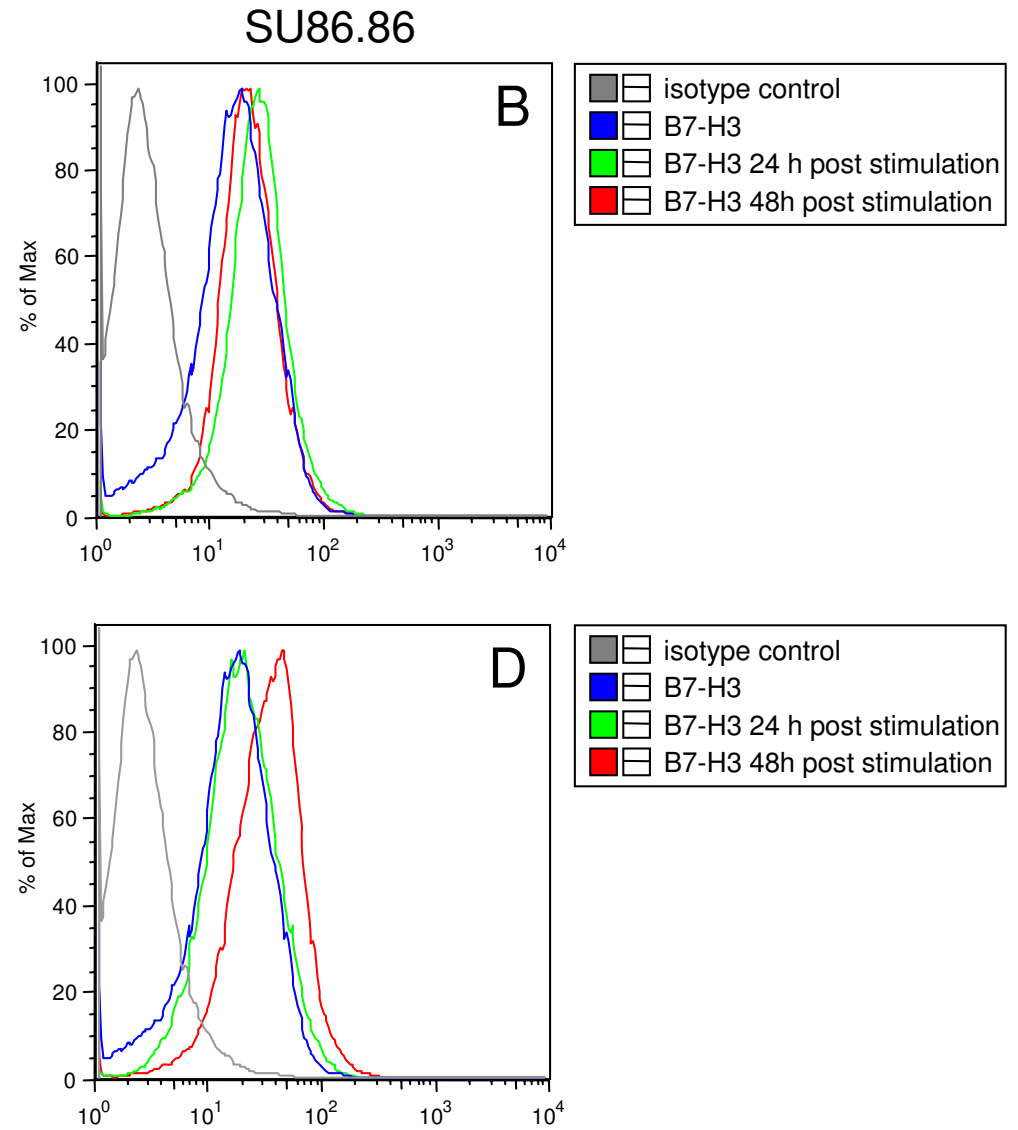

Figure 4

Effects of treatment with IFN- $\gamma$ or IL-4 on Panc-I and SU86.86 pancreatic cancer cells. Cells were treated with either $2000 \mathrm{IU} / \mathrm{ml}$ of recombinant IFN- $\gamma$ or $40 \mathrm{ng} / \mathrm{ml}$ of recombinant IL-4 for 24 or 48 hours and analyzed by FACS. (B) IFN- $\gamma$ treatment resulted in a marked increase of B7-H3 expression on SU86.86 cells after 24 hours (green line) and 48 hours (red line). (D) IL-4 treatment resulted in a marked increase of B7-H3 expression on SU86.86 cells after 48 hours (red line), but not after 24 hours (green line). In contrast, (A) IFN- $\gamma$ treatment led to a slight decrease of B7-H3 expression on Panc-I cells 24 hours after stimulation (green line) with normalization 48 hours after stimulation (red line). (C) IL-4 treatment led to a slight decrease of B7-H3 expression on Panc-I cells 24 hours after stimulation (green line) and 48 hours after stimulation (red line). The blue lines display B7-H3 expression without stimulation by IFN- $\gamma$ and IL-4. The grey lines display the (isotope) control group.

gene expression in pancreatic cancer tissues significantly correlated with the levels of CD4 and CD8. Further immunohistochemical analyses on the distribution of CD4+ and CD8+ T cells revealed the infiltration of CD4+ and CD8+ T cells into areas of B7-H3 positive pancreatic cancer cells. More importantly, the number of tumor-infiltrating CD8+ T cells significantly correlated with the levels of B7-H3 on pancreatic cancer cells. Therefore, one could speculate that tumor-associated $\mathrm{B} 7-\mathrm{H} 3$ expression might act as a positive regulator of antitumor response in pancreatic cancer. B7-H3 might trigger the infiltration of CD8+ T cells into cancerous tissues and might also enhance tumor immunogenicity by stimulation of tumorinfiltrating CD8+ T cells. These findings are in accordance with previous reports on the function of B7-H3. Chapoval and colleagues reported that human $\mathrm{B} 7-\mathrm{H} 3$ costimulates proliferation of CD8+ T cells, enhances the induction of cytotoxic $\mathrm{T}$ cells, and selectively stimulates IFN- $\gamma$ production by $\mathrm{T}$ cells in the presence of $\mathrm{T}$ cell receptor signaling in vitro [17]. Further data in support of a positive costimulatory role of $\mathrm{B} 7-\mathrm{H} 3$ in the regulation of immune response come from an experimental study showing that acute and chronic cardiac allograft rejection can be reduced in B7-H3 knock-out mice [26]. Recently, B7-H3 has also been implicated as a potential stimulator of antitumor immunity. In vivo, transfection of B7-H3 into P815 mouse tumors led to tumor regression and amplification of tumor-specific CD8+ CTL response in syngeneic mice suggesting enhancement of tumor immunogenicity by preferential stimulation of CD8 $+\mathrm{T}$ cell responses [19]. 

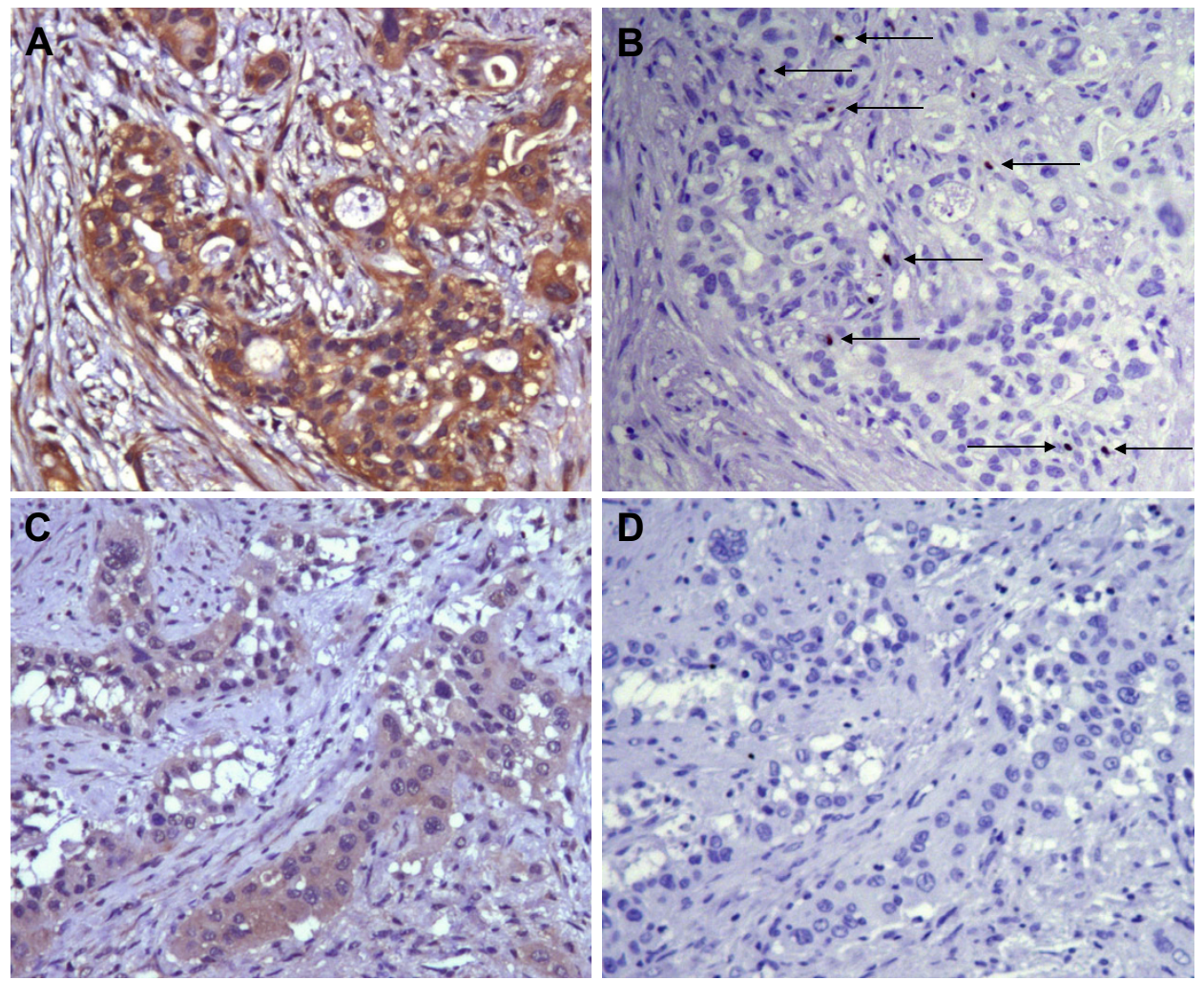

Figure 5

Representative immunohistochemical stainings for B7-H3 (A, C) and CD8 (B, D) in pancreatic cancer tissues. (A) Pancreatic cancer tissue section with strong B7-H3 immunoreactivity. (B) Consecutive section with immunostaining for CD8 shows the infiltration of numerous CD8+ T cells (arrows). (C) Pancreatic cancer tissue section with weak tumor B7-H3 immunoreactivity. (D) Consecutive section with immunostaining for CD8 shows no CD8+ tumor-infiltrating T cells.

Further evidence in favor of a possible tumor-protective effect of B7-H3 expression in cancers comes from a clinical study investigating the expression of B7-H3 in human gastric carcinoma. The majority of tumors showed B7-H3 expression in tumor cells. Moreover, the presence of B7H3 positive tumor cells was associated with improved patient survival [27]. Although these results clearly implicate a tumor-protective effect of $\mathrm{B} 7-\mathrm{H} 3$, the exact physiologic/pathologic role of $\mathrm{B} 7-\mathrm{H} 3$ remains ambiguous, because $\mathrm{B} 7-\mathrm{H} 3$ has also been shown to inhibit CD4+ and CD8+ T cell proliferation and IFN- $\gamma$ production mediated by anti-CD3 in mice [28]. Recently, single or duplicate constructs of the immunoglobulin-V-like and immunoglobulin-C-like domains of B7-H3 have been shown to downregulate both $\mathrm{T}$ cell proliferation and cytokine production in response to CD3/CD28-mediated costimulatory activation [29]. Further evidence that B7-H3 may serve as an inhibitor of antitumor immunity includes several clinical studies. In prostate cancer, Zang et al. evaluated the expression of $\mathrm{B} 7-\mathrm{H} 3$ in over eight hundred prostate cancer patients and reported that $93 \%$ of the examined tumors displayed aberrant B7-H3 expression
[23]. High tumor B7-H3 expression was associated with disease progression and spread as well as with poor patient survival [23]. Accordingly, tumor cell and tumor vasculature B7-H3 expression significantly correlated with an increased risk of death from clear cell renal cell carcinoma [30]. In these studies, however, the functional aspect of B7-H3 expression was not tested in detail. For example, correlation of B7-H3 expression by cancer cells with tumor-infiltrating immune cells was either not tested or not significant. The reason for the contrasting effects of B7-H3 in cancer might also be related to varying counterreceptors involved in different tumor entities. So far, one receptor of $\mathrm{B} 7-\mathrm{H} 3$ has been identified [31]. Hashiguchi and co-workers have recently reported that murine $\mathrm{B} 7-\mathrm{H} 3$ specifically binds to triggering receptor expressed on myeloid cells (TREM)-like transcript 2 (TLT-2, TREML2), which is expressed on both CD4+ and CD8+ T cells [31]. Moreover, the authors demonstrated that stimulation with B7-H3 transfectants preferentially upregulated the proliferation and IFN- $\gamma$ production of $\mathrm{CD}^{+} \mathrm{T}$ cells [31]. In humans, however, a receptor for $\mathrm{B} 7-\mathrm{H} 3$ has not been identified yet. 


$$
\begin{gathered}
\text { CD8+ T cells } \\
(p=0.018)
\end{gathered}
$$

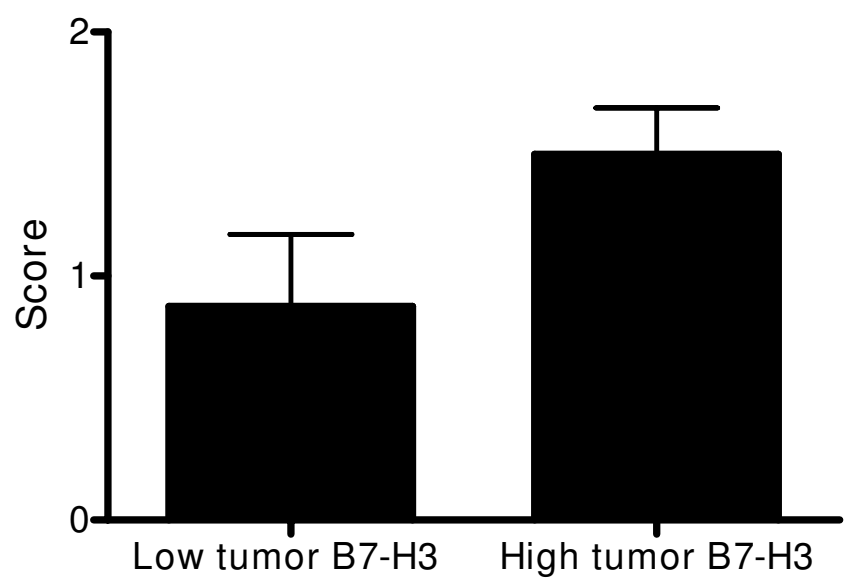

Figure 6

Semi-quantitative analysis of CD8+ T cells in pancreatic cancer. In areas with high tumor $\mathrm{B} 7-\mathrm{H} 3$ expression, the prevalence of CD8+ T cells was significantly increased compared to areas with low tumor B7-H3 expression ( $\mathrm{P}=$ $0.018)$.

Another possible mechanism involved in antitumor immunity includes the induction of tumor-suppressive cytokines. Here, we found that B7-H3 was significantly associated with IFN- $\gamma$ levels. IFN- $\gamma$ is an important proinflammatory Th1 cytokine and has been implicated as a mediator of an extrinsic tumor-suppressor mechanism in immunocompetent hosts. IFN- $\gamma$ is usually produced by activated cytotoxic T lymphocytes, macrophages, and natural killer (NK) cells [32]. In mice, treatment with neutralizing monoclonal antibodies to IFN- $\gamma$ resulted in a faster growth of immunogenic sarcomas that were transplanted into mice [33]. Furthermore, endogenously produced IFN- $\gamma$ has been shown to be protective against transplanted, chemically induced, and spontaneous tumors [34]. Therefore, B7-H3 might act as an immunostimulatory agent through the induction of IFN- $\gamma$.

Mechanisms regulating B7-H3 expression are still unclear. The local cytokine milieu in the tumor microenvironment represents a potential regulator of B7-H3. Indeed, IFN- $\gamma$ has previously been shown to enhance surface expression of B7-H3 on bone marrow derived dendritic cells and on monocytes [18]. Therefore, we investigated the potential effects of the Th 1 cytokine IFN- $\gamma$ and Th 2 cytokine IL- 4 on the expression of $\mathrm{B} 7-\mathrm{H} 3$ on cultured pancreatic cancer cells. We found that both IFN- $\gamma$ and IL-4 treatment resulted in a marked increase of B7-H3 on SU86.86 but not on Panc-1 pancreatic cancer cells. Furthermore, we found that B7-H3 positively correlated with IFN- $\gamma$ levels in vivo. Taken together, these findings suggest a potential involvement of IFN- $\gamma$ (and IL-4) in the regulation of B7H3 expression in pancreatic cancer.

\section{Conclusion}

We demonstrated for the first time that B7-H3 is abundantly expressed in pancreatic cancer and that tumor cellassociated B7-H3 expression significantly correlates with prolonged postoperative survival. Moreover, we showed that B7-H3 expression significantly correlated with the number of tumor-infiltrating CD8+ T cells. Although further functional studies will certainly be required to better understand the exact role of $\mathrm{B} 7-\mathrm{H} 3$ in pancreatic cancer, our data suggest that B7-H3 might be involved in the induction of a specific antitumor immune response and that treatment with $\mathrm{B} 7-\mathrm{H} 3$ (e.g. by gene transfer) might represent a promising approach to improve the outcome of pancreatic cancer patients.

\section{Abbreviations}

CTLA-4: Cytotoxic T lymphocyte-associated antigen-4; IFN- $\gamma$ : Interferon-gamma; IL-2: Interleukin-2; IL-4: Interleukin-4; qRT-PCR: Quantitative real-time polymerase chain reaction.

\section{Competing interests}

The authors declare that they have no competing interests.

\section{Authors' contributions}

ML and DMH conceived and designed the study, analyzed the data and drafted the manuscript. ML and NG supplied tissue specimens and collected clinical data. ML, DMH, and MO carried out immunohistochemical stainings. ML, $\mathrm{DMH}$, and IE were responsible for the evaluation of immunohistochemistry data. DMH and ML performed the FACS analyses. NG carried out the qRT-PCRs. ML, JK, and HF provided expert guidance throughout the preparation of the manuscript, and reviewed the manuscript.

All authors read and approved the final manuscript.

\section{Acknowledgements}

We thank B. Bentzinger, E. Mohr, M. Meinhardt and P. Schmidbauer for excellent technical assistance.

\section{References}

I. Jemal A, Siegel R, Ward E, Hao Y, Xu J, Murray T, Thun MJ: Cancer statistics, 2008. CA Cancer J Clin 2008, 58(2):7I-96.

2. Kleeff J, Michalski C, Friess H, Buchler MW: Pancreatic cancer: from bench to 5-year survival. Pancreas 2006, 33(2): I I I- I I8.

3. Wagner M, Redaelli C, Lietz M, Seiler CA, Friess H, Buchler MW: Curative resection is the single most important factor determining outcome in patients with pancreatic adenocarcinoma. Br J Surg 2004, 9 I(5):586-594.

4. Dong H, Strome SE, Salomao DR, Tamura H, Hirano F, Flies DB, Roche PC, Lu J, Zhu G, Tamada K, et al.: Tumor-associated B7-HI promotes T-cell apoptosis: a potential mechanism of immune evasion. Nat Med 2002, 8(8):793-800. 
5. Gajewski TF, Meng $\mathrm{Y}$, Harlin $\mathrm{H}$ : Immune suppression in the tumor microenvironment. J Immunother 2006, 29(3):233-240.

6. Laheru D, Jaffee EM: Immunotherapy for pancreatic cancer science driving clinical progress. Nat Rev Cancer 2005, 5(6):459-467.

7. Greenwald RJ, Freeman GJ, Sharpe AH: The B7 family revisited. Annu Rev Immunol 2005, 23:5 I5-548.

8. Krummel MF, Allison JP: CTLA-4 engagement inhibits IL-2 accumulation and cell cycle progression upon activation of resting T cells. J Exp Med 1996, I 83(6):2533-2540.

9. Dong H, Zhu G, Tamada K, Chen L: B7-HI, a third member of the B7 family, co-stimulates T-cell proliferation and interleukin-I0 secretion. Nat Med 1999, 5(1 2): 1365-1369.

10. Sica GL, Choi IH, Zhu G, Tamada K, Wang SD, Tamura H, Chapoval Al, Flies DB, Bajorath J, Chen L: B7-H4, a molecule of the B7 family, negatively regulates T cell immunity. Immunity 2003, I 8(6):849-86I.

II. Konishi J, Yamazaki K, Azuma M, Kinoshita I, Dosaka-Akita H, Nishimura M: B7-HI expression on non-small cell lung cancer cells and its relationship with tumor-infiltrating lymphocytes and their PD-I expression. Clin Cancer Res 2004, I 0(15):5094-5 I00.

12. Nomi T, Sho M, Akahori T, Hamada K, Kubo A, Kanehiro H, Nakamura S, Enomoto K, Yagita H, Azuma M, et al:: Clinical significance and therapeutic potential of the programmed death-I ligand/programmed death-I pathway in human pancreatic cancer. Clin Cancer Res 2007, I3(7):2 I5I-2I 57.

13. Loos M, Giese NA, Kleeff J, Giese T, Gaida MM, Bergmann F, Laschinger $M, M W B$, Friess $H$ : Clinical significance and regulation of the costimulatory molecule $\mathrm{B} 7-\mathrm{HI}$ in pancreatic cancer. Cancer Lett 2008, 268(I):98-109.

14. Ohigashi Y, Sho M, Yamada Y, Tsurui Y, Hamada K, Ikeda N, Mizuno $T$, Yoriki R, Kashizuka H, Yane $K$, et al:: Clinical significance of programmed death-I ligand-I and programmed death-I ligand-2 expression in human esophageal cancer. Clin Cancer Res 2005, I I (8):2947-2953.

15. Thompson RH, Kuntz SM, Leibovich BC, Dong H, Lohse CM, Webster WS, Sengupta S, Frank I, Parker AS, Zincke H, et al:: Tumor B7. $\mathrm{HI}$ is associated with poor prognosis in renal cell carcinoma patients with long-term follow-up. Cancer Res 2006, 66(7):3381-3385.

16. Nakanishi J, Wada Y, Matsumoto K, Azuma M, Kikuchi K, Ueda S: Overexpression of B7-HI (PD-LI) significantly associates with tumor grade and postoperative prognosis in human urothelial cancers. Cancer Immunol Immunother 2007, 56(8): II73-II82.

17. Chapoval Al, Ni J, Lau JS, Wilcox RA, Flies DB, Liu D, Dong H, Sica GL, Zhu G, Tamada K, et al:: B7-H3: a costimulatory molecule for $\mathbf{T}$ cell activation and IFN-gamma production. Nat Immunol 200I, 2(3):269-274.

18. Suh WK, Gajewska BU, Okada H, Gronski MA, Bertram EM, Dawicki W, Duncan GS, Bukczynski J, Plyte S, Elia A, et al.: The B7 family member B7-H3 preferentially down-regulates $\mathrm{T}$ helper type I-mediated immune responses. Nat Immunol 2003, 4(9):899-906.

19. Luo L, Chapoval AI, Flies DB, Zhu G, Hirano F, Wang S, Lau JS, Dong $H$, Tamada $K$, Flies AS, et al.: B7-H3 enhances tumor immunity in vivo by costimulating rapid clonal expansion of antigenspecific CD8+ cytolytic T cells. I Immunol 2004 I 73(9):5445-5450.

20. Lupu CM, Eisenbach C, Lupu AD, Kuefner MA, Hoyler B, Stremme W, Encke J: Adenoviral B7-H3 therapy induces tumor specific immune responses and reduces secondary metastasis in a murine model of colon cancer. Oncol Rep 2007, 18(3):745-748.

21. Sun X, Vale M, Leung E, Kanwar JR, Gupta R, Krissansen GW: Mouse B7-H3 induces antitumor immunity. Gene Ther 2003, I0(20): 1728-1734.

22. Sun Y, Wang Y, Zhao J, Gu M, Giscombe R, Lefvert AK, Wang X: B7$\mathrm{H} 3$ and $B 7-\mathrm{H} 4$ expression in non-small-cell lung cancer. Lung Cancer 2006, 53(2): |43-|5|.

23. Zang X, Thompson RH, Al-Ahmadie HA, Serio AM, Reuter VE, Eastham JA, Scardino PT, Sharma P, Allison JP: B7-H3 and B7x are highly expressed in human prostate cancer and associated with disease spread and poor outcome. Proc Natl Acad Sci USA 2007, I 04(49): 19458-19463.
24. Roth T], Sheinin Y, Lohse CM, Kuntz SM, Frigola X, Inman BA, Krambeck AE, McKenney ME, Karnes RJ, Blute ML, et al.: B7-H3 ligand expression by prostate cancer: a novel marker of prognosis and potential target for therapy. Cancer Res 2007, 67(16):7893-7900.

25. Erkan M, Kleeff J, Esposito I, Giese T, Ketterer K, Buchler MW, Giese NA, Friess H: Loss of BNIP3 expression is a late event in pancreatic cancer contributing to chemoresistance and worsened prognosis. Oncogene 2005, 24(27):442I-4432.

26. Wang L, Fraser CC, Kikly K, Wells AD, Han R, Coyle AJ, Chen L, Hancock WW: B7-H3 promotes acute and chronic allograft rejection. Eur I Immunol 2005, 35(2):428-438.

27. Wu CP, Jiang JT, Tan M, Zhu YB, Ji M, Xu KF, Zhao JM, Zhang GB, Zhang XG: Relationship between co-stimulatory molecule B7$\mathrm{H} 3$ expression and gastric carcinoma histology and prognosis. World J Gastroenterol 2006, I 2(3):457-459.

28. Prasad DV, Nguyen T, Li Z, Yang Y, Duong J, Wang Y, Dong C: Murine B7-H3 is a negative regulator of T cells. I Immunol 2004, I 73(4):2500-2506.

29. Ling V, Wu PW, Spaulding V, Kieleczawa J, Luxenberg D, Carreno BM, Collins M: Duplication of primate and rodent B7-H3 immunoglobulin V-and C-like domains: divergent history of functional redundancy and exon loss. Genomics 2003, 82(3):365-377.

30. Crispen PL, Sheinin Y, Roth TJ, Lohse CM, Kuntz SM, Frigola X, Thompson RH, Boorjian SA, Dong $\mathrm{H}$, Leibovich BC, et al.: Tumor cell and tumor vasculature expression of $\mathrm{B} 7-\mathrm{H} 3$ predict survival in clear cell renal cell carcinoma. Clin Cancer Res 2008, I4(16):5।50-5I57.

3I. Hashiguchi M, Kobori H, Ritprajak P, Kamimura Y, Kozono H, Azuma $M$ : Triggering receptor expressed on myeloid cell-like transcript 2 (TLT-2) is a counter-receptor for B7-H3 and enhances $\mathbf{T}$ cell responses. Proc Natl Acad Sci USA 2008, 105(30): 10495-10500.

32. Kalvakolanu DV, Borden EC: An overview of the interferon system: signal transduction and mechanisms of action. Cancer Invest 1996, I4(I):25-53.

33. Bui JD, Carayannopoulos LN, Lanier LL, Yokoyama WM, Schreiber RD: IFN-dependent down-regulation of the NKG2D ligand H60 on tumors. J Immunol 2006, I 76(2):905-913

34. Chang CJ, Chen YH, Huang KW, Cheng HW, Chan SF, Tai KF, Hwang LH: Combined GM-CSF and IL- 12 gene therapy synergistically suppresses the growth of orthotopic liver tumors. Hepatology 2007, 45(3):746-754

\section{Pre-publication history}

The pre-publication history for this paper can be accessed here:

\section{http://www.biomedcentral.com/1471-2407/9/463/pre} pub

\section{Publish with Biomed Central and every scientist can read your work free of charge}

"BioMed Central will be the most significant development for disseminating the results of biomedical research in our lifetime. "

Sir Paul Nurse, Cancer Research UK

Your research papers will be:

- available free of charge to the entire biomedical community

- peer reviewed and published immediately upon acceptance

- cited in PubMed and archived on PubMed Central

- yours - you keep the copyright
BioMedcentral 